\title{
Level of physical activity, well-being, stress and self-rated health in persons with migraine and co-existing tension-type headache and neck pain
}

Lotte Skytte Krøll ${ }^{1,2^{*}}$, Catharina Sjödahl Hammarlund ${ }^{1}$, Maria Lurenda Westergaard ${ }^{2}$, Trine Nielsen², Louise Bönsdorff Sloth², Rigmor Højland Jensen ${ }^{2}$ and Gunvor Gard ${ }^{1}$

\begin{abstract}
Background: The prevalence of migraine with co-existing tension-type headache and neck pain is high in the general population. However, there is very little literature on the characteristics of these combined conditions. The aim of this study was to investigate a) the prevalence of migraine with co-existing tension-type headache and neck pain in a clinic-based sample, b) the level of physical activity, psychological well-being, perceived stress and selfrated health in persons with migraine and co-existing tension-type headache and neck pain compared to healthy controls, c) the perceived ability of persons with migraine and co-existing tension-type headache and neck pain to perform physical activity, and d) which among the three conditions (migraine, tension-type headache or neck pain) is rated as the most burdensome condition.
\end{abstract}

Methods: The study was conducted at a tertiary referral specialised headache centre where questionnaires on physical activity, psychological well-being, perceived stress and self-rated health were completed by 148 persons with migraine and 100 healthy controls matched by sex and average age. Semi-structured interviews were conducted to assess characteristics of migraine, tension-type headache and neck pain.

Results: Out of 148 persons with migraine, 100 (67\%) suffered from co-existing tension-type headache and neck pain. Only $11 \%$ suffered from migraine only. Persons with migraine and co-existing tension-type headache and neck pain had lower level of physical activity and psychological well-being, higher level of perceived stress and poorer self-rated health compared to healthy controls. They reported reduced ability to perform physical activity owing to migraine (high degree), tension-type headache (moderate degree) and neck pain (low degree). The most burdensome condition was migraine, followed by tension-type headache and neck pain.

Conclusions: Migraine with co-existing tension-type headache and neck pain was highly prevalent in a clinic-based sample. Persons with migraine and co-existing tension-type headache and neck pain may require more individually tailored interventions to increase the level of physical activity, and to improve psychological well-being, perceived stress and self-rated health.

Keywords: Migraine, Neck pain, Physical activity, Psychological well-being, Tension-type headache, Self-rated health, Stress

\footnotetext{
* Correspondence: lotte.skytte.kroell@regionh.dk

${ }^{1}$ Department of Health Sciences, Lund University, P.O. Box 157, 22100 Lund,

Sweden

2Danish Headache Centre, Department of Neurology, Rigshospitalet-Glostrup,

University of Copenhagen, Nordre Ringvej 69, 2600 Glostrup, Denmark
} 


\section{Background}

The prevalence of migraine in Europe is 15\% [1], and persons with migraine often suffer from co-morbidities such as tension-type headache (TTH) and neck pain (NP). In a population study, $94 \%$ of persons with migraine reported co-existing TTH [2], and NP was found among $89.3 \%$ of persons with migraine with co-existing TTH [3]. The prognosis of migraine may worsen with co-existing TTH [4], and NP has been found to be a predictor of increased disability in persons with migraine [5].

This study focuses on persons with migraine and coexisting TTH and NP. There is very little literature on the characteristics of persons with migraine and coexisting TTH and NP. There are, to our knowledge, no studies that describe their symptomatology, physical activity, psychological well-being, perceived stress or self-rated health. These characterizations are important when considering potential treatment strategies.

It is not known whether specific nonpharmacological treatments could be particularly helpful for persons with migraine and co-existing TTH and NP. Lifestyle modifications like exercise, relaxation and biofeedback are recommended nonpharmacological strategies for persons with migraine [6-9]. These modalities may also be effective in treating the coexisting TTH and NP [10-13].

The aim of this study was to investigate a) the prevalence of migraine and co-existing TTH and NP in a clinic-based sample, b) the level of physical activity, psychological well-being, perceived stress and self-rated health in persons with migraine and co-existing TTH and NP compared to healthy controls, c) the perceived ability of persons with migraine and co-existing TTH and NP to perform physical activity, and d) which among the three conditions (migraine, TTH or NP) is rated as the most burdensome condition.

\section{Methods}

\section{Participants}

Two hundred persons with migraine aged 18-65, screened for exclusion criteria and who initially accepted participation were consecutively recruited from a tertiary referral headache centre between February 2014 and March 2015148 (74\%) returned the questionnaires and were included in the study (Fig. 1).

Exclusion criteria were: whiplash injury, significant neck trauma (defined as a history of trauma to the neck, fracture, distortion and violent attack which have caused

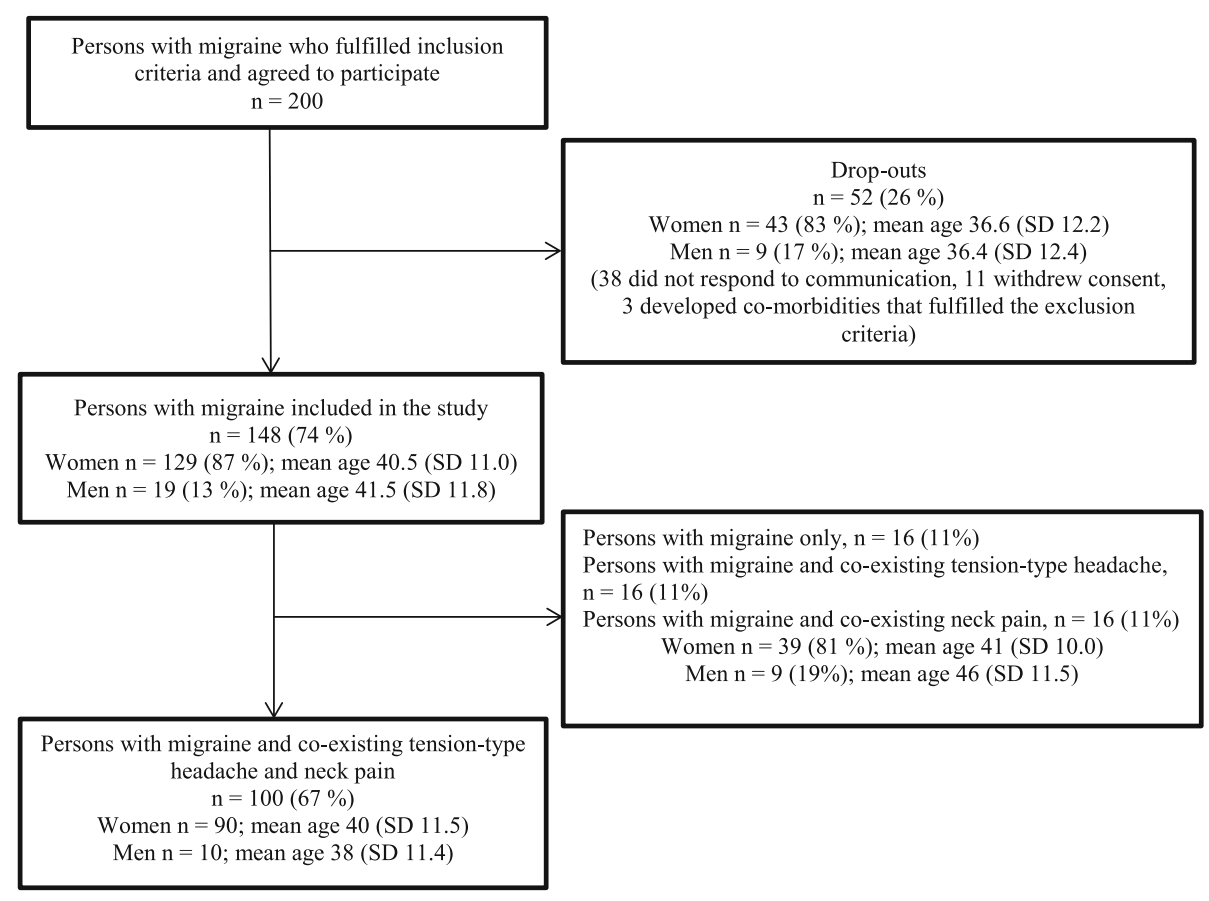

Healthy controls $\mathrm{n}=100$

Women $\mathrm{n}=91$; mean age $39.32($ SD 9.67)

Men $\mathrm{n}=9$; mean age 36.67 (SD 14.89)

Fig. 1 Flow chart of the inclusion procedure of a clinic-based sample of persons with migraine 
the current NP), post traumatic headache, medicationoveruse headache, cluster headache, trigeminal neuralgia, pregnancy and/or breastfeeding, severe physical and/or mental diseases, abuse of alcohol or drugs and inability to speak or understand Danish.

Between June 2014 and October 2015, 100 headachefree and healthy controls were recruited among hospital staff by modified snowball sampling and advertisement. Exclusion criteria were abuse of alcohol or drugs, inability to speak and understand Danish, regular intake of analgesics, NP and TTH frequency $\geq 1$ day per month.

The healthy controls were matched to the included persons with migraine by the average value of age and the percentage distribution of sex.

\section{Procedure}

The participants with migraine $(n=148)$ and healthy controls $(n=100)$ completed three questionnaires which were validated for the target population in a previous study [14]; (a) The International Physical Activity Questionnaire (IPAQ short form) [15], (b) the 5-item World Health Organization Well-Being Index (WHO-5) [16] and (c) Impact of Migraine, Tension-Type Headache and Neck Pain (Impact of Migraine, TTH and NP) [14]. A maximum of three reminders were sent out.

\section{Interview}

\section{Migraine, TTH and NP}

The participants filled out a 4-week diagnostic headache diary before the first visit in the headache centre. Based on data from the diary and a neurological examination the neurologist ascertained the diagnosis of migraine. They were then interviewed using a modified semistructured headache interview $[17,18]$ which was supplemented with questions regarding NP. NP was defined as pain located to the anatomic region of the neck with or without radiation to the head, trunk, and upper limbs grade I-II, based on the classification system developed by the Neck Pain Task Force [19], which have set a conceptual model for the onset, course, and care of NP.

To distinguish NP from NP associated with the migraine attack itself and NP outside the migraine attack the participants were asked: "Do you have NP associated with the migraine attack?" "Do you have NP associated with TTH?” "Do you have NP without headache?"

The screening for inclusion and exclusion criteria and all interviews were done by specially trained medical students (TN, LBS) and the primary investigator (LSK). The semi-structured headache interview [17] was originally based on International Classification of Headache Disorders (ICHD) criteria from 1988 [20], but the interview guide provided enough information to classify migraine and TTH according to the ICHD-3 beta criteria
[21]. Based on the interview, the one-year prevalence and average days of migraine, TTH and NP per month were determined.

\section{Questionnaires \\ IPAQ short form}

The level of physical activity was measured using the IPAQ short form [14, 15]. IPAQ measures time and energy expenditure in the past 7 days. Participants were classified as having low, moderate or high levels of physical activity based on the standard algorithm [22]. The IPAQ protocol considers performed physical activity and their corresponding metabolic equivalent task (MET). One MET is equivalent to energy expenditure while resting. Participants were excluded from the analyses if they answered "don't know/insecure" in any of the categories of walking, moderate or vigorous physical activity, and if time spent on any of the categories were unreasonably high.

\section{WHO-5}

Psychological well-being was measured by WHO-5 [16], which is based on five items with a two-week recall period. Responses were rated on six-point Likert categories (0 to 5$)$. The scores were summed (maximum score 25) and then multiplied by 4 (range 0 to 100 with lower scores indicate lower well-being). The cut-off level of $\leq 50$ was used to indicate poor psychological wellbeing, which may indicate stress or depression [23].

\section{Impact of Migraine, TTH and NP questionnaire}

The Impact of Migraine, TTH and NP questionnaire consists of 79 items covering pain, triggers, psychosocial, socioeconomic and work related aspects, based on a four-week recall period. The questionnaire has previously been tested for face and content validity [14]. The following items were analysed in this study: perceived stress, self-rated health, the perceived ability to perform physical activity and rating of the most burdensome condition. Perceived stress and perceived ability to perform physical activity were rated on an 11-point numeric rating scale (NRS-11) with the end points $0=$ no impact and $10=$ most imaginable impact as applied in previous studies [24, 25].

Perceived stress was assessed by a reliable and valid item from the QPS Nordic Questionnaire [26]: "Stress means the situation when a person feels tense, restless, nervous, or anxious, or is unable to sleep at night because his or her mind is troubled all the time. In the past four weeks, did you feel that kind of stress these days?" Responses ranged from 0 (not at all) to 10 (very high degree). To be able to analyse the different levels of perceived stress, we coded scores $0-3$ as low, scores 4-6 as moderate and 7-10 as high. 
Self-rated health was assessed by one item, originally derived from SF 36 [27]: "In general, how would you rate your current health?" The response categories were: 1) very poor, 2) poor, 3) fair, 4) good or 5) very good. The variable was changed to a binary categorical variable "poor self-rated health" as applied in previous studies [3, 28]. Scores 1-3 were coded as poor selfrated health.

Perceived ability to perform physical activity was assessed by three items: "In the past four weeks, when having migraine/TTH/NP, how much has your ability to perform physical activity (physical activity or strength training) been reduced?" Responses ranged from 0 (not reduced) to 10 (reduced to a very high degree).

Rating of the most burdensome condition was assessed by one item: "In the past four weeks, to what extent does your migraine, TTH and NP generally affect you? If you consider all three conditions as adding up to 100\%, to what extent does each of these conditions affect you?"

\section{Statistical analysis}

Data on demography, lifestyle and clinical characteristics of the participants were presented with descriptive statistics.

In comparing migraine and co-existing $\mathrm{TTH}$ and NP with the control group, Independent-samples t-test was used to test for differences in age as age was tested as normally distributed by the Shapiro-Wilk test. Chi-square test was used to test for difference in sex, educational attainment, physical activity, psychological well-being, stress and self-rated health.

A significant difference in educational attainment between migraine and co-existing TTH and NP and healthy controls was observed. Low educational level is associated with reduced health and low level of physical activity [29], therefore, separate binary logistic regressions were performed with migraine and co-existing TTH and NP as the outcome variable and the following as covariates: Physical activity (low, moderate and high), psychological well-being (score $\leq 50$, yes or no), perceived stress (low, moderate and high), and poor self-rated health (yes or no). These analyses were controlled for educational attainment. Results from the logistic regression were presented as odds ratios $(\mathrm{OR})$ with $95 \%$ confidence intervals $(\mathrm{CI})$.

All statistical analyses were performed using IBM SPSS version 22. Statistical significance was assumed when $p<0.05$.

\section{Results}

The 148 persons with migraine included in the study were comprised of 106 (72\%) who had migraine without aura, 8 (5\%) who had migraine with aura, and 34 (23\%) who had both migraines with and without aura. Among them, 100 (67\%) suffered from co-existing TTH and NP. Only $11 \%$ suffered from migraine only $(n=16), 11 \%$ suffered from migraine and co-existing TTH $(n=16)$, and $11 \%$ had migraine and co-existing NP $(n=16)$.

Data on the participants' demographic characteristics, educational attainment, physical activity, psychological well-being, perceived stress, self-rated health, headache and NP are summarized in Table 1 . There were no differences in sex and age, but educational attainment was significantly different, between migraine and co-existing TTH and NP and healthy controls.

NP associated with the migraine attack was reported by $54 \%$, NP associated with TTH was reported by $94 \%$ and NP without headache was reported by $66 \%$.

Persons with migraine and co-existing TTH and NP were significantly less physically active, reported significantly lower psychological well-being, had higher levels of perceived stress and poorer self-rated health compared to healthy controls (Table 1).

Logistic regression analyses controlled for educational attainment showed that migraine and co-existing TTH and NP were strongly associated with physical activity, psychological well-being, perceived stress and poor selfrated health (Table 2).

For persons with migraine and co-existing TTH and NP, the ability to perform physical activity was highly reduced because of migraine (median score of 9 on a rating scale from $0-10$ ), moderately reduced because of TTH (median 5 ) and less reduced because of NP (median 3).

Almost half of the persons with migraine and coexisting TTH and NP (48\%) rated migraine as the most burdensome of the three conditions. TTH was rated as the most burdensome condition by $30 \%$, and NP was rated as the most burdensome condition by $10 \%$. Migraine and TTH were rated as equally burdensome by $6 \%$, all three conditions as equally burdensome by $3 \%$ and TTH and NP by $3 \%$.

\section{Discussion}

To the best of our knowledge, this is the first study to investigate the prevalence of migraine and co-existing TTH and NP in a clinical migraine population and to evaluate physical activity, psychological well-being, perceived stress and self-rated health in this subset of persons with migraine.

The prevalence of migraine with co-existing TTH and NP differed from the population-based study by Ashina et al. [3] that found a one-year prevalence of $\mathrm{NP}$ of $89.3 \%$ in persons suffering from migraine and co-existing TTH. The difference may be due to the sub-grouping of participants applied by Ashina et al. that investigated NP in persons with migraine and coexisting TTH. Molarius and Tegelberg [28] reported findings similar to ours although their case ascertainment was not based on ICHD-criteria. 
Table 1 Health-related variables, headache and neck pain frequencies in persons with co-existing M, TTH and NP

\begin{tabular}{|c|c|c|c|c|}
\hline & $\begin{array}{l}\text { All } \\
N=148\end{array}$ & $\begin{array}{l}M-T T H-N P \\
N=100\end{array}$ & $\begin{array}{l}\text { Healthy controls } \\
N=100\end{array}$ & $\begin{array}{l}p \text { value } \\
M \text {-TTH-NP } \\
\text { healthy controls }\end{array}$ \\
\hline Age, mean (SD) & $41(11.1)$ & $40(11.4)$ & $39(10.2)$ & 0.49 \\
\hline Sex, $n(\%)$ & & & & 0.81 \\
\hline Women & $129(87)$ & 90 & 91 & \\
\hline Men & $19(13)$ & 10 & 9 & \\
\hline Educational attainment, $n$ (\%) & & & & 0.014 \\
\hline$<3$ years higher education & $57(40)$ & 42 & 26 & \\
\hline$\geq 3$ years higher education & $85(60)$ & 56 & 73 & \\
\hline Missing, $n$ & 6 & 2 & 1 & \\
\hline Physical activity ${ }^{\mathrm{a}}, n(\%)$ & & & & 0.001 \\
\hline Low & $29(23)$ & $18(21)$ & $7(8)$ & \\
\hline Moderate & $50(40)$ & $34(41)$ & $25(27)$ & \\
\hline High & $47(37)$ & $32(38)$ & $59(65)$ & \\
\hline Missing, $n$ & 22 & 16 & 9 & \\
\hline Psychological well-being $\leq 50^{\mathrm{b}}, n(\%)$ & & & & $<0.001$ \\
\hline No & $75(51)$ & 48 & 89 & \\
\hline Yes & $73(49)$ & 52 & 11 & \\
\hline Missing, $n$ & 1 & 1 & & \\
\hline Stress ${ }^{\complement}, n(\%)$ & & & & $<0.001$ \\
\hline Low & $61(42)$ & 38 & 66 & \\
\hline Moderate & $33(22)$ & 22 & 21 & \\
\hline High & $53(36)$ & 39 & 13 & \\
\hline Missing, $n$ & 1 & 1 & & \\
\hline Poor self-rated health ${ }^{d}$ & & & & $<0.001$ \\
\hline No & $58(39)$ & 38 & 96 & \\
\hline Yes & $90(61)$ & 62 & 4 & \\
\hline Migraine days/month, median (q1, q3) & $6(4,10)$ & $6(3,10)$ & - & - \\
\hline TTH days/month, median (q1, q3) & $9(4,18)$ & $9(4,15)$ & - & - \\
\hline NP days/month, median (q1, q3) & $11.5(5,30)$ & $13(5,30)$ & - & - \\
\hline Chronic migraine, n (\%) & $41(28)$ & 28 & - & - \\
\hline Chronic TTH, $n(\%)$ & $21(14)$ & 17 & - & - \\
\hline Chronic NP, n (\%) & $54(37)$ & 49 & - & - \\
\hline
\end{tabular}

Independent-samples t-test was used to test for differences in age; Chi-square test was used to test for difference in sex, educational attainment, physical activity, psychological well-being, stress and poor self-rated health

$M$ migraine, NP neck pain, $n$ numbers, $q$ quartiles, $q 1$ and $q 3$ refer to first and third quartiles, SD standard deviation, $T T H$ tension-type headache

${ }^{a}$ Assessed using the International Physical Activity Questionnaire (IPAQ short form) low, moderate and high physical activity was based on time and energy expenditure in the past 7 days

${ }^{\mathrm{b}}$ Assessed using the World Health Organisation five-item Well-Being Index (WHO-5) sum score from 0-100; sores $\leq 50$ indicate poor psychological well-being

${ }^{\mathrm{C}}$ Assessed using stress scores with end-points $0=$ no stress at all and $10=$ very high degree of stress; scores $0-3=$ low, scores $4-6=$ moderate, scores $7-10=$ high stress

${ }^{d}$ Assessed using self-rated health with end-points $1=$ very poor to $5=$ very good; scores $1-3$ indicated poor self-rated health

In accordance with our study Varkey et al. [30] found that persons with migraine were less physically active compared to headache-free individuals and low physical activity was associated with a higher prevalence of migraine. Interestingly, in a population study, Ashina et al. [31] found that low physical activity was associated with migraine and co-existing $\mathrm{TTH}$ to a higher degree compared to other types of headache and the association was stronger with TTH than migraine only. Physical activity may be a potential migraine treatment strategy to reduce migraine frequency, pain intensity and duration [6]. Both physical activity and stress reduction strategies have been suggested to increase the quality of life [32-34]. Moreover, systematic stress management, 
Table 2 Odds ratios of co-existing M, TTH and NP and health-related variables controlled for educational attainment

\begin{tabular}{|c|c|c|c|c|}
\hline & $\mathrm{OR}^{\mathrm{a}}(95 \% \mathrm{Cl})$ & $p$ value & $\mathrm{OR}^{\mathrm{b}}(95 \% \mathrm{Cl})$ & $p$ value \\
\hline \multicolumn{5}{|c|}{$\overline{\text { Physical activity }^{c}}$} \\
\hline High & Ref & & Ref & \\
\hline Moderate & $2.5(1.28-4.91)$ & 0.007 & $2.7(1.35-5.36)$ & 0.005 \\
\hline Low & $4.7(1.79-12.55)$ & 0.002 & $4.4(1.62-11.72)$ & 0.004 \\
\hline Missing, $n$ & 16 & & & \\
\hline \multicolumn{5}{|c|}{ Psychological well-being $\leq 50^{d}$} \\
\hline No & Ref & & Ref & \\
\hline Yes & $8.8(4.19-18.36)$ & $<0.001$ & $9.3(9.35-19.86)$ & $<0.001$ \\
\hline Missing, $n$ & 1 & & & \\
\hline \multicolumn{5}{|l|}{ Stress ${ }^{\mathrm{e}}$} \\
\hline Low & Ref & & Ref & \\
\hline Moderate & $1.8(0.89-3.73)$ & 0.103 & $1.6(0.74-3.32)$ & 0.238 \\
\hline High & $5.2(2.48-10.96)$ & $<0.001$ & $6.0(2.78-12.98)$ & $<0.001$ \\
\hline Missing & 1 & & & \\
\hline \multicolumn{5}{|c|}{ Poor self-rated health ${ }^{f}$} \\
\hline No & Ref & & Ref & \\
\hline Yes & $39.2(13.32-115.15)$ & $<0.001$ & $37.7(12.77-111.52)$ & $<0.001$ \\
\hline \multicolumn{5}{|c|}{$\begin{array}{l}\text { The analyses were conducted by binary logistic regression and estimated as } \mathrm{OR} \text { and } 95 \% \mathrm{Cl} \\
\mathrm{Cl} \text { confidence interval, } M \text { migraine, } N P \text { neck pain, } \mathrm{OR} \text { odds ratio, Ref reference value, } T \mathrm{H} \text { tension-type headache } \\
\text { a } \mathrm{OR}=\text { unadjusted } \\
\mathrm{b} \mathrm{OR}=\text { adjusted for educational attainment } \\
{ }^{\mathrm{C}} \text { Assessed using the International Physical Activity Questionnaire (IPAQ short form) low, moderate and high physical activity was based on time and energy } \\
\text { expenditure in the past } 7 \text { days } \\
{ }^{\mathrm{d}} \text { Assessed using the World Health Organisation five-item Well-Being Index (WHO-5) sum score from } 0 \text { to } 100 \text {; sores } \leq 50 \text { indicate poor psychological well-being } \\
{ }^{2} \text { Assessed using stress scores with end-points } 0=\text { no stress at all and } 10=\text { very high degree of stress; scores } 0-3=\text { low, scores } 4-6=\text { moderate, scores } 7-10=\text { high stress } \\
\text { fAssessed using self-rated health with end-points } 1=\text { very poor to } 5=\text { very good; scores } 1-3 \text { indicated poor self-rated health }\end{array}$} \\
\hline
\end{tabular}

such as progressive muscle relaxation, reduced migraine frequency [7] and a relaxation program has been shown to be effective in persons with headache and neck/shoulder pain [12].

The characteristics of the participants with migraine and co-existing TTH and NP reflect the findings of other studies on the impact of migraine on psychological well-being, an association with increased stress and poor self-rated health [28, 35-37]. Schramm et al. [37] did not find any differences in the level of perceived stress between those with migraine only and those with migraine and co-existing TTH. Molarius and Tegelberg [28] found that persons with migraine and recurrent headache reported poorer self-rated health than those with migraine only. Reduced psychological well-being may indicated stress or depression [23]. Persons with migraine are in general very susceptible to stress $[38,39]$ and have higher levels of stress compared to headachefree individuals [37] which is in line with our findings.

This study showed that persons with migraine and coexisting TTH and NP had very low level of physical activity, and their perceived ability to perform physical activity was reduced not only owing to migraine (to a high degree) but also TTH and NP (to a lesser degree), although almost 50\% suffered from chronic NP. In contrast to our study, the population study by Ashina et al. [31] found a higher association between low physical activity and $\mathrm{TTH}$ only, than between low physical activity and migraine only. Compared to the population study, we recruited persons with migraine which can explain these different results.

Our results suggest that persons with migraine and co-existing TTH and NP may have more barriers to perform physical activity compared to those with migraine only, even though TTH and NP were not rated as quite as burdensome. Decreased psychological well-being, high perceived stress and low self-rated health among those with migraine and co-existing TTH and NP suggest conditions that may make it more difficult to motivate this group to increase their levels of physical activity.

Migraine, TTH and NP are complex and multi-factorial disorders. It is important to consider implementing multidisciplinary treatment strategies when these three conditions are co-existing $[40,41]$. Whether a physiotherapeutic treatment modality such as physical activity has a mutual or complementary effect on migraine and coexisting TTH and NP has yet to be investigated. 
Strengths of this study were that the participants' diagnoses were based on a 4-week diagnostic headache diary before their first visit in the headache centre together with a detailed headache history and a neurological examination. Also, an additional interview was conducted to ascertain characteristics of migraine, TTH and NP. This procedure reduced the risk of misclassification and excluded other neurological diseases. The ICHD 3-beta criteria for migraine and TTH were used, and NP was described using the classification system by the Neck Pain Task Force [19]. Also, all participants were presented with a drawing of the anatomic region of the neck in order to standardise descriptions of NP distribution area.

The response rate of persons with migraine with returned questionnaire was relatively high $[3,28]$ making our estimate of the one-year prevalence of migraine with co-existing TTH and NP relatively strong.

We used three different variables (psychological wellbeing, perceived stress and self-rated health) as measures of health-related quality of life. These represent different domains and together give a good indication of the headache burden and what is important to consider when deciding a relevant treatment strategy and/or outcome measures for migraine and co-existing TTH and NP.

Limitations of the study were that participants were recruited from one tertiary referral headache centre and may, therefore, not represent the total migraine population. The participants had a relatively high prevalence of both chronic migraine (28\%) and chronic TTH (17\%), which may explain our large proportion of persons with migraine and co-existing TTH and NP. Further, such a clinical sample may be more aware of their symptoms and more capable of distinguishing between migraine and TTH than the general migraine population.

Most of the healthy controls were recruited among healthcare professionals, and were generally more highly educated than the persons with migraine and co-existing TTH and NP and they were more physically active than the persons with migraine and co-existing TTH and NP and the general population [42]. However, they were very close to the general population regarding sum scores of psychological well-being [43]. Education was therefore considered as a confounding factor in the regression analyses.

Self-report on physical activity, psychological wellbeing, stress and self-rated health may increase the risk of recall-bias. Personal interview is stronger than selfreport in reducing recall bias, and might have prevented the exclusion of participants who had inadequate answers in the IPAQ questionnaire. The drawback is that interview may cause interviewer bias. Prospective diary recording of migraine and co-existing TTH and NP together with personal interview may have been more ideal as diagnostic tools [44].
Detailed history and diary recording are particularly important for ascertaining multiple diagnoses. In the future, a larger sample of participants would allow for separate analyses of those with migraine only and migraine with either co-existing TTH or NP. This would also allow controlling for migraine disability.

There is a risk of losing power when collapsing responses into few categories, however, these categories are more informative and easier to explain to patients.

\section{Conclusions}

Migraine and co-existing TTH and NP was highly prevalent in a clinical sample of persons with migraine. Persons with migraine and co-existing TTH and NP reported significantly lower level of physical activity and psychological well-being; higher level of perceived stress, and poorer self-rated health than healthy controls. Persons with migraine and co-existing TTH and NP reported a reduced ability to perform physical activity owing to all three conditions with migraine as the most burdensome condition followed by TTH and NP. Persons with migraine and co-existing TTH and NP may require more focused interventions to increase physical activity. Whether physical activity is a beneficial treatment modality for this group is not known, and should be investigated in a clinical trial.

\section{Abbreviations \\ Cl: Confidence interval; ICHD: International classification of headache disorders; IPAQ: International physical activity questionnaire; MET: Metabolic equivalent task; NP: Neck pain; OR: Odds ratio; TTH: Tension-type headache; WHO-5: The World Health Organization 5-item Well-Being Index}

\section{Acknowledgement}

The authors wish to thank all participants, the clinicians and technicians at Rigshospitalet-Glostrup for their cooperation.

\section{Funding}

The study was supported by the Medical Faculty of Lund University, Lund, Sweden and the Danish Headache Centre, Rigshospitalet-Glostrup, Denmark. The study was financially supported by research grants from RigshospitaletGlostrup, Lundbeck Foundation, Aase and Ejnar Danielsen's Foundation, Cool Sorption Foundation of 1989, Danish Physical Therapists' foundation for research, education and practice development, The Association of Danish Physiotherapists' Practice Foundation and The Danish Migraine and Headache Association. Our funders had no influence over the structure of analytical methods or the presented results.

Availability of data and materials

Data will not be shared as they are a part of ongoing studies.

\section{Authors' contributions}

LSK, CSH, MLW, RHJ, GG study design, manuscript preparation and editing. LSK, TN, LBS data acquisition. LSK, TN database management. MLW statistical considerations and language editing. LSK performed the statistical analysis. All authors read and approved the final version of the manuscript.

Competing interests

The authors declare that they have no competing interests.

Consent for publication

Not applicable. 


\section{Ethics approval and consent to participate}

All participants received oral and written information, and all signed an informed consent form. Personal data were deleted in accordance to the requirements of the Danish Data Protection Agency. The local ethical committee of the Capital Region of Denmark approved the study, protocol no H-1-2011-090. The study was conducted in accordance with the Declaration of Helsinki.

\section{Publisher's Note}

Springer Nature remains neutral with regard to jurisdictional claims in published maps and institutional affiliations.

\section{Received: 6 February 2017 Accepted: 6 April 2017}

Published online: 18 April 2017

\section{References}

1. Stovner LJ, Andree C (2010) Prevalence of headache in Europe: a review for the Eurolight project. J Headache Pain 11:289-299

2. Lyngberg AC, Rasmussen BK, Jorgensen $T$, Jensen $R$ (2005) Has the prevalence of migraine and tension-type headache changed over a 12-year period? A Danish population survey. Eur J Epidemiol 20:243-249

3. Ashina S, Bendtsen L, Lyngberg AC, Lipton RB, Hajiyeva N, Jensen R (2015) Prevalence of neck pain in migraine and tension-type headache: a population study. Cephalalgia 35:211-219

4. Lyngberg AC, Rasmussen BK, Jorgensen T, Jensen R (2005) Prognosis of migraine and tension-type headache: a population-based follow-up study. Neurology 65:580-585

5. Ford S, Calhoun A, Kahn K, Mann J, Finkel A (2008) Predictors of disability in migraineurs referred to a tertiary clinic: neck pain, headache characteristics, and coping behaviors. Headache 48:523-528

6. Luedtke K, Allers A, Schulte LH, May A (2016) Efficacy of interventions used by physiotherapists for patients with headache and migraine-systematic review and meta-analysis. Cephalalgia 36:474-492

7. Meyer B, Keller A, Wohlbier HG, Overath CH, Muller B, Kropp P (2016) Progressive muscle relaxation reduces migraine frequency and normalizes amplitudes of contingent negative variation (CNV). J Headache Pain 17:37

8. Nestoriuc Y, Martin A, Rief W, Andrasik F (2008) Biofeedback treatment for headache disorders: a comprehensive efficacy review. Appl Psychophysiol Biofeedback 33:125-140

9. Silberstein SD (2016) Considerations for management of migraine symptoms in the primary care setting. Postgrad Med 128:523-537

10. Andersen LL, Mortensen OS, Zebis MK, Jensen RH, Poulsen OM (2011) Effect of brief daily exercise on headache among adults-secondary analysis of a randomized controlled trial. Scand J Work Environ Health 37:547-550

11. Mongini F, Ciccone G, Rota E, Ferrero L, Ugolini A, Evangelista A, Ceccarelli M, Galassi C (2008) Effectiveness of an educational and physical programme in reducing headache, neck and shoulder pain: a workplace controlled trial. Cephalalgia 28:541-552

12. Rota E, Evangelista A, Ceccarelli M, Ferrero L, Milani C, Ugolini A, Mongini F (2016) Efficacy of a workplace relaxation exercise program on muscle tenderness in a working community with headache and neck pain: a longitudinal, controlled study. Eur J Phys Rehabil Med 52:457-465

13. Soderberg E, Carlsson J, Stener-Victorin E (2006) Chronic tension-type headache treated with acupuncture, physical training and relaxation training. Between-group differences. Cephalalgia 26:1320-1329

14. Krøll LS, Hammarlund CS, Jensen RH, Gard G (2015) Migraine co-existing tension-type headache and neck pain: Validation of questionnaires. Scand J Pain 8:10-16

15. Craig $C L$, Marshall AL, Sjostrom M, Bauman AE, Booth ML, Ainsworth BE, Pratt M, Ekelund U, Yngve A, Sallis JF, Oja P (2003) International physical activity questionnaire: 12-country reliability and validity. Med Sci Sports Exerc 35:1381-1395

16. Bech P (2012) The clinical consequence of IRT analyses: Health-related quality of life. In: Clinical psychometrics, vol 1. Wiley-Blackwell, Chichester, West Sussex, pp 74-94

17. Rasmussen BK, Jensen R, Olesen J (1991) Questionnaire versus clinical interview in the diagnosis of headache. Headache 31:290-295

18. Russell MB, Rasmussen BK, Thorvaldsen P, Olesen J (1995) Prevalence and sex-ratio of the subtypes of migraine. Int J Epidemiol 24:612-618
19. Guzman J, Hurwitz EL, Carroll L, Haldeman S, Cote P, Carragee EJ, Peloso PM, van der Velde G, Holm LW, Hogg-Johnson S, Nordin M, Cassidy JD (2009) A new conceptual model of neck pain: linking onset, course, and care: the Bone and Joint Decade 2000-2010 Task Force on Neck Pain and Its Associated Disorders. J Manipulative Physiol Ther 32:S17-\$28

20. Headache Classification Committee of the International Headache Society (1988) Classification and diagnostic criteria for headache disorders, cranial neuralgias and facial pain. Cephalalgia 8(Suppl 7):1-96

21. Headache Classification Committee of the International Headache Society (IHS (2013)). The International Classification of Headache Disorders, 3rd edition (beta version). Cephalalgia 33:629-808

22. Guidelines for Data Processing and Analysis of the International Physical Activity Questionnaire (IPAQ) - Short and Long Forms (2005) IPAQ International Physical Activity Questionnaire. Available via www.ipaq.ki.se. Accessed 21 Nov 2016

23. Topp CW, Ostergaard SD, Sondergaard S, Bech P (2015) The WHO-5 Well-Being Index: a systematic review of the literature. Psychother Psychosom 84:167-176

24. Hjermstad M, Fayers PM, Haugen DF, Caraceni A, Hanks GW, Loge JH, Fainsinger R, Aass N, Kaasa S (2011) Studies comparing Numerical Rating Scales, Verbal Rating Scales, and Visual Analogue Scales for assessment of pain intensity in adults: a systematic literature review. J Pain Symptom Manage 41:1073-1093

25. Hockings RL, McAuley JH, Maher CG (2008) A systematic review of the predictive ability of the Orebro Musculoskeletal Pain Questionnaire. Spine (Phila Pa 1976) 33:E494-E500

26. Lindström K, Björklund C, Mykletun RJ, Furunes T, Gard G, Pahkin K (2008) Nordic Questionnaire for Monitoring the Age Diverse Workforce Review report of QPS Nordic-ADW. Nordic Council of Ministers, Copenhagen

27. Bjorner JB, Thunedborg K, Kristensen TS, Modvig J, Bech P (1998) The Danish SF-36 Health Survey: translation and preliminary validity studies. J Clin Epidemiol 51:991-999

28. Molarius A, Tegelberg A (2006) Recurrent headache and migraine as a public health problem-a population-based study in Sweden. Headache 46:73-81

29. Shaw BA, Spokane LS (2008) Examining the association between education level and physical activity changes during early old age. J Aging Health 20:767-787

30. Varkey E, Hagen K, Zwart JA, Linde M (2008) Physical activity and headache: results from the Nord-Trondelag Health Study (HUNT). Cephalalgia 28:1292-1297

31. Ashina S, Bendtsen L, Lyngberg AC, Lipton RB, Hajiyeva N, Jensen R (2013) Association of lower level of leisure-related physical activity with primary headaches. Cephalalgia 33:145

32. Dittrich SM, Gunther V, Franz G, Burtscher M, Holzner B, Kopp M (2008) Aerobic exercise with relaxation: influence on pain and psychological well-being in female migraine patients. Clin J Sport Med 18:363-365

33. Narin SO, Pinar L, Erbas D, Ozturk V, Idiman F (2003) The effects of exercise and exercise-related changes in blood nitric oxide level on migraine headache. Clin Rehabil 17:624-630

34. Varkey E, Cider A, Carlsson J, Linde M (2011) Exercise as migraine prophylaxis: a randomized study using relaxation and topiramate as controls. Cephalalgia 31:1428-1438

35. Dahlof CG, Dimenas E (1995) Migraine patients experience poorer subjective well-being/quality of life even between attacks. Cephalalgia 15:31-36

36. Dueland AN, Leira R, Cabelli ST (2005) The impact of migraine on psychological well-being of young women and their communication with physicians about migraine: a multinational study. Curr Med Res Opin 21:1297-1305

37. Schramm SH, Moebus S, Lehmann N, Galli U, Obermann M, Bock E, Yoon MS, Diener HC, Katsarava Z (2015) The association between stress and headache: A longitudinal population-based study. Cephalalgia 35:853-863

38. Kelman $L$ (2007) The triggers or precipitants of the acute migraine attack. Cephalalgia 27:394-402

39. Spierings EL, Ranke AH, Honkoop PC (2001) Precipitating and aggravating factors of migraine versus tension-type headache. Headache 41:554-558

40. Gaul C, van Doorn C, Webering N, Dlugaj M, Katsarava Z, Diener HC, Fritsche G (2011) Clinical outcome of a headache-specific multidisciplinary treatment program and adherence to treatment recommendations in a tertiary headache center: an observational study. J Headache Pain 12:475-483

41. Jensen R, Zeeberg P, Dehlendorff C, Olesen J (2010) Predictors of outcome of the treatment programme in a multidisciplinary headache centre. Cephalalgia 30:1214-1224 
42. Bauman A, Bull F, Chey T, Craig CL, Ainsworth BE, Sallis JF, Bowles HR, Hagstromer M, Sjostrom M, Pratt M (2009) The International Prevalence Study on Physical Activity: results from 20 countries. Int J Behav Nutr Phys Act 6:21

43. Bech P, Olsen LR, Kjoller M, Rasmussen NK (2003) Measuring well-being rather than the absence of distress symptoms: a comparison of the SF-36 Mental Health subscale and the WHO-Five Well-Being Scale. Int J Methods Psychiatr Res 12:85-91

44. Phillip D, Lyngberg A, Jensen R (2007) Assessment of headache diagnosis. A comparative population study of a clinical interview with a diagnostic headache diary. Cephalalgia 27:1-8

\section{Submit your manuscript to a SpringerOpen ${ }^{\circ}$ journal and benefit from:}

- Convenient online submission

- Rigorous peer review

- Immediate publication on acceptance

- Open access: articles freely available online

- High visibility within the field

- Retaining the copyright to your article

Submit your next manuscript at springeropen.com 